\title{
Infâncias, Gênero e Sexualidades: Uma Investigação- Intervenção com Professores de Educação Indantil
}

\author{
Children, Gender and Sexualities: An Action-Research with \\ Teachers of Early Childhood Education
}

\author{
Eduardo Benedito Cólis * \\ Leonardo Lemos de Souza
}

Universidad Estadual Paulista Julio de Mesquita Filho, Brasil

\begin{abstract}
O objetivo deste estudo foi conhecer o processo de subjetivação dos professores sobre gênero, sexualidade e infância em suas práticas educativas. Foi realizada uma pesquisa-intervenção com o objetivo de dialogar com os educadores de um Centro Local de Educação Infantil. Realizaram-se oficinas e entrevistas para coletar dados. Identificamos o uso de tecnologias de gênero pelos professores na produção de infâncias padronizadas e como a escola atua como um agente que coloca essa padronização em ação. Dentre elas identificamos formas de atuar no processo pedagógico junto às crianças, a força de discursos como o da identificaçao das sexualidades a partir dos estereotipos binários de gênero, bem como das intervenções no sentido de corrigir os desvios de rota das sexualidades e dos gêneros. Ao mesmo tempo percebemos os os efeitos do brincar e a relação do mecanismo sexo/gênero que perpassam as brincadeiras pela mediação dos adultos e os discursos naturalizantes e normalizadores. A pesquisa se propôs a criar um espaço de formação e debate entre pesquisador e educadoras em que problematizações sobre as normalizações sobre gêneros e sexualidades pudessem ser colocados em movimento. Finaliza-se detenco considerações sobre as posibilidades de potencia da educação infantil em romper desde cedo os discursos binários e heternormativos sobre gêneros e sexualidades.
\end{abstract}

Palavras-chave: Gênero; Comportamento sexual; Educação básica; Entrevista; Estereótipos.

The aim of this study was to know the subjectivation process of teachers about gender, sexuality and childhood in their educational practices. For this, an intervention research was conducted with the purpose of organizing dialogues with early childhood educators of a Municipal Center of Early Childhood Education. Workshops and interviews were conducted to collect data. We identified the use of gender technologies by teachers in the production of normalized childhoods, and how the school acts as an agent that puts this normalization into action. Among them, we identified ways of acting in the pedagogical process with children, the strength of discourses such as the identification of sexualities based on binary gender stereotypes, as well as interventions to correct deviations in the route of sexualities and genders. We perceive the effects of play and the relationship of the sex / gender mechanism that permeates play through the mediation of adults and the naturalizing and normalizing discourses. The research aimed to create a space for training and debate between researcher and educators in which questions about the normalization of genders and sexualities could be put in motion. It concludes with some considerations about the potential possibilities of early childhood education in breaking from binary and heternormative discourses about genders and sexualities from an early age.

Keywords: Gender roles; Sexual behaviour; Basic education; Interview; Stereotypes.

*Contacto: eduardocolis@outlook.com

Recibido: 10/11/2019

$1^{a}$ Evaluación: 15/01/2020

ISSN: 0718-7378

Aceptado: 07/03/2020

www.rinace.net/rlei/ 


\section{Introducción}

Este artigo foi elaborado a partir da experiência de pesquisa em um curso de mestrado acadêmico em Psicologia e Sociedade da Universidade Estadual Paulista, cujo objetivo foi propor uma investigação que envolvesse a educação como um campo intenso de aprendizado, afeto, resistência, produção. subjetividades e convivência social. Partimos dos discursos produzidos nas narrativas dos professores das creches sobre suas experiências com o tema sexualidade e gênero na infância.

A educação infantil foi o campo escolhido para propor problematizações, a fim de trazer à superfície as experiências intrínsecas da prática profissional dos educadores e suas relações com as políticas educacionais. Assim, apresentamos os efeitos de uma pesquisaintervenção produzida por nós em um centro educacional, com o objetivo de fazer emergir os processos de subjetivação sobre gêneros, sexualidades e infância, na perspectiva dos educadores de infância convidados a falar sobre o assunto.

A questão da infância e sua interseção com gêneros e sexualidades é destacada no contexto político e educacional em que se observa rejeição e perseguição contra grupos de dissidentes. Com isso, são atualmente identificadas as implicações na normalização da infância, nas quais as expressões das crianças em busca da heterossexualidade hegemônica são privadas das experiências de meninos e meninas jovens e suas inscrições em sexos e sexualidades normais (Rodrigues et al., 2018).

De acordo com Rohden (2009) a escola, como agente que impõe disciplina e normas, produz efeitos sociais que são produzidos nas desigualdades sociais dos gêneros desde a infância. Além disso, poderemos pensar sobre as implicações dos discursos dos educadores da infância como efeitos dos discursos culturais e políticos. Dessa forma, "é essencial saber o que os professores pensam sobre educação, sobre as expressões de sexualidade que ocorrem diariamente na escola e na maneira como trabalham com essas expressões" (Gesser et al., 2012, p. 234).

Com o decorrer do processo, os educadores organizaram caminhos e trabalhos para essas discussões, cuja principal tendência é analisar as tecnologias de gênero na produção de infâncias normalizadas, dessa forma, "os corpos sofrem a ação das tecnologias de gênero, criando discursos sobre sua forma, aparência e funcionalidade.

(Maia, 2018, p. 124)

A investigação dos processos de subjetivação de infâncias, gêneros e sexualidades a partir das experiências de educadores de um centro de educação infantil nos deu pistas sobre os efeitos que as práticas pedagógicas sobre sexualidades e gêneros exercem sobre o corpo e a existência de crianças em suas creches.

Dentre as principais investigações e discussões sobre estudos de gênero e sexualidade, podemos citar vários autores que contribuíram para esse importante tópico que ganhou força no Brasil nas últimas décadas, conforme enfatizado por Buss-Simão (2013). Sobre a educação infantil também podemos destacar os trabalhos de Jane Felipe (2007, 2011), Claudia Vianna e Daniela finco (2009).

Assim, o presente trabalho busca contribuir com os estudos desses atravessamentos (infância, gênero e sexualidade) no campo da educação de crianças pequenas. Preocupa-se com a perspectiva de uma educação em que exista uma prática envolvida com a democracia, com a análise da inclusão da diferença, principalmente nas trajetórias de vida de crianças e jovens em relação a seus gêneros e sexualidades. 


\section{Revisão de literatura}

Apresentamos dois tópicos necessários para a compreensão do campo de nossa pesquisa. Um primeiro tópico que lida com os conceitos de gênero, sexualidade e os processos de subjetivação envolvidos nos discursos e práticas dos educadores na infância. Um segundo tópico trata das pesquisas realizadas nas últimas décadas sobre o assunto, que as informa sobre as diferentes análises necessárias para mudar as práticas educacionais excludentes e que tornam invisíveis as sexualidades e os gêneros.

A questão das sexualidades e gêneros tem uma longa história desenvolvida a partir de estudos feministas e estudos queer. Destacamos sobre ela o conceito de tecnologias de gênero (Lauretis, 1987; Preciado, 2002) e o dispositivo da sexualidade (Foucault, 1999).

Quando pensamos na complexidade e pluralidade atribuídas à terminologia "gênero", de acordo com Teresa de Lauretis (1987), podemos pensar na influência dos vários dispositivos sociais e relacionais representados por esse termo ", portanto, o gênero não representa um indivíduo e sim uma relação, um relacionamento social; em outras palavras, representa um indivíduo através de uma classe” (p. 211). É necessário enfatizar que o gênero como dispositivo social se baseia na lógica binária (homem/mulher), conforme determinado pelo contexto social, que exclui outras experiências que fogem dessa hegemonia.

Teresa de Lauretis (1987) propõe que os estudos feministas proponham reflexões sobre a “(in)gestação” de dispositivos sexuais (biológicos) e de gênero (construção sociocultural), assim os espaços foram delimitados pela especificidade de gêneros (gerados) "Em que a diferença sexual pode ser afirmada, tratada, analisada, especificada ou verificada" (Lauretis, 1987, p. 206).

Para que o gênero seja incorporado na esfera social como uma relação de poder, é essencial observar que existem várias tecnologias que subsidiam e naturalizam a dinâmica sexo / gênero, pois consideramos que “[ $[.$.$] a sexualidade não é apenas uma questão pessoal, mas$ social e política. [...] O fato de a sexualidade ser "aprendida”, ou melhor, é construída, ao longo da vida, de várias maneiras, por todos os sujeitos” (Louro, 2000, p. 8), levando em consideração que o termo tecnologia não está apenas vinculado aos aparatos tecnológicos que legitimam os efeitos sociais do gênero, mas de todas as maneiras pelas quais essa lógica é propagada (principalmente por meio de discursos).

Expandimos essa discussão com Preciado (2002). Para ele, as tecnologias de gênero apoiam a dominação das expressões femininas e a diversidade sexual como um todo, portanto, todos os que fogem da lógica dominante (gays, lésbicas, travestis, transexuais, entre outros) são vítimas dos efeitos aspectos sociais da naturalização dessas tecnologias, nas quais podemos expandir ainda mais a dicotomia de gênero, atribuindo as características específicas de outros marcadores sociais (religião, gênero, classe, etnia, idade) que intensificarão esses efeitos.

Ainda assim, se pensarmos na amplitude de maneiras que legitimam as tecnologias de gênero, podemos pensar em quão questionáveis são as proposições naturais implícitas nos discursos sociais (principalmente os fundamentalistas e religiosos) que precisamos desconstruir à medida que ocorrem. Mecanismos de problematização e valoração da diferença. $\mathrm{Na}$ inserção dos corpos nos gêneros da lógica fundamental que os regula, 
podemos aprofundar as diferenças nas quais cada grupo propõe novas referências que objetivam identidades sexuais (Preciado, 2002).

Enquanto isso, percebe-se como as relações de poder são pulverizadas nas relações sociais. Assim, é essencial trazer as produções de Foucault (1999) a respeito do poder sobre a vida, chamadas por ele como biopoder dissolvidas nas várias disciplinas que Eles apresentam várias instituições sociais (escola, igreja, saúde, judicial, etc.). Considerando as interseções de gêneros e sexualidades inseridas no livro História da Sexualidade - volume I no qual analisa como os discursos sobre corpos e desejo (normativo) criam regularidades sobre quem devemos ser e fazer. $\mathrm{O}$ conceito de dispositivo foucaltiano revela esse fato em redes e relações emaranhadas nas quais o biopoder, enquanto nega e inibe, produz efeitos. Desse modo, a ideia de uma repressão à sexualidade como algo que a proíbe e controla, a produz e deve mantê-la através de várias estratégias de poder.

Diante dessa perspectiva, não pretendemos apresentar a identidade sexual como rígida e rápida, mas sim fluida e singular, pois o problema está instalado no momento em que essas construções ocorrem diante de imposições sociais que moldam e anulam essas expressões singulares.

Num segundo tópico, apresentamos estudos da educação infantil sobre sexualidade e gênero. Destacamos a relação da educação infantil com o feminismo à luz das lutas contra o patriarcado; a feminilidade da educação infantil e do machismo; os educadores seus discursos e práticas com as diferenças de meninos e meninas; os desafios da educação infantil diante do contexto político e social brasileiro da rejeição de questões de gênero e sexualidade. Não pode-se deixar de apontar os efeitos do patriarcado no contexto social e institucional, que influenciam diretamente as produções dos processos de subjetivação na lógica do gênero como dispositivo de controle social no contexto da educação infantil.

Para que as discussões sobre sexualidade e gênero sejam inseridas em contextos educacionais, os educadores devem estar cientes das curiosidades que o sexo pode proporcionar, questionando até suas próprias experiências, para que os efeitos dessa discussão sejam refletidos no na infância e, no caso dos educadores de infantil, é necessário discutir e problematizar as questões de gênero e inclusão, assim como no contexto do trabalho (Silva e Luz, 2010).

Desde uma perspectiva histórica, torna-se necessário discutir, questionar e problematizar as questões sociais aplicadas às questões de gênero na educação infantil. Paschoal e Machado (2009) apontam que no Brasil a necessidade de cuidado em relação à criança mais nova decorre de instituições filantrópicas e assistenciais e não pedagógicas como na Europa, que se propõe a erradicar as necessidades de crianças abandonadas ou foram negligenciados por seus parentes, uma vez que a criança não era valorizada, pois o desprezo e os maus-tratos eram um costume da sociedade em geral. Portanto, diante das altas taxas de mortalidade infantil e de práticas higienistas (de limpar as ruas de crianças abandonadas), foram criadas no Brasil instituições que acolhem essa população. Um exemplo é a Roda dos Expostos que recebeu crianças abandonadas devido ao efeito da lógica do patriarcado em esconder a vergonha das mães solteiras.

Percebemos o processo histórico de que as diferenças denominadas desigualdade de gênero (principalmente associadas à sexualidade das mulheres) e como efeito a institucionalização de crianças de natureza filantrópica e assistencialista, reformuladas ao 
longo dos anos no Brasil com o Extinção da roda daqueles expostos apenas no século XX, por volta de 1950, segundo Paschoal e Machado (2009).

Didonet (2001) propõe que as políticas da infância começaram a ser incorporadas a partir de 1940, diante da figura da mãe-operarária (afirmando a lógica da criança não estar sob os cuidados da mãe trabalhadora) e com a finalidade de aperfeiçoar a criança como sujeito de educação, que corrobora com a ideia de não apenas "culpar" a mãe criando uma lógica que envolva a criança como pessoa em desenvolvimento. Isso desencadeia a promoção de políticas que envolvam a formulação de um novo modelo histórico envolvendo a criança como principal agente, não apenas como uma prioridade para a mãe que trabalha, mas para a criança e si, que está em desenvolvimento.

Nesse contex to histórico e político, são iniciadas políticas para atender às necessidades das mulheres (luta feminista e sindical) e da infância, uma vez que o Estado cria mecanismos (até hoje) para lidar com as demandas sociais e os direitos das crianças e adolescentes, das mulheres na sociedade, permeando o olhar pela desigualdade social e de gênero, pelos cuidados demandados pelas infâncias em tenra idade.

Campos (1999) destaca que os movimentos de mulheres trabalhadoras nas indústrias e no setor de serviços estão incorporados às diretrizes de negociação, incluindo a assistência à infância, na qual o impacto desses movimentos não ocorre imediatamente no setor educacional e de assistência social e relações trabalhistas. Muitas vezes as mulheres que compõem esse movimento passam a trabalhar em creches, como mão-de-obra barata e sem formação profissional, enfrentando longas e difíceis horas de trabalho. No que diz respeito aos processos pedagógicos, estes foram dirigidos apenas para grupos de crianças com idade próxima a sete anos, assim os berçários iam atender a população mais pobre, de maneira paralela e segregada.

Outro ponto importante é o fato de um trabalho docente atribuído às mulheres, a feminização da profissão docente. De acordo com Rosa (2011), esse é um fator que atribui estereótipos de gêneros e determina papéis sociais definidos pelas subordinações das mulheres. É importante lembrar que esse processo histórico de feminização da profissão docente ocorre de maneira conflituosa, por constantes lutas, o lugar do professor não é mais ocupado por homens, e as mulheres que ganham força nesse território, principalmente na educação de crianças muito pequenas.

Fúlvia Rosemberg (2002) realiza vários estudos que demonstram na história da educação infantil de países desenvolvidos e subdesenvolvidos, com abordagens comparativas sobre o cuidado da criança, que destacam uma certa noção de abrangência da educação nos países desenvolvidos e de maneira fragmentada nos países subdesenvolvidos.

No Brasil, crianças de 0 a 6 anos de idade foram reconhecidas como sujeitos de direitos somente com a Constituição de 1988 e após os anos seguintes com a implementação da Lei 8.069 de 1990, que institui o Estatuto da Criança e do Adolescente. Posteriormente, as políticas foram implementadas para essa faixa etária, por meio da Lei de Diretrizes e Bases da Educação (LDB, 1996), que implementou a Educação Infantil como primeira etapa da educação básica, um grande avanço histórico e social para a realidade brasileira, porque "é uma direito da criança e visa proporcionar condições adequadas para o desenvolvimento do bem-estar da criança, como desenvolvimento físico, motor, emocional, social, intelectual e expansão de suas experiências "(Paschoal e Machado, 2009, p. 80). 
Essas diretrizes supramencionadas formam a base de um importante marco histórico da Educação Infantil, tendo em vista que este documento se refere à estrutura de práticas pedagógicas por eixos que garantem a educação de forma a garantir sua abrangência, favorecendo as experiências das crianças na Educação Básica com qualidade, implementando a lógica dos princípios fundamentais: ético, político e estético.

Atualmente, a educação infantil ainda sofre com as brechas históricas da lógica filantrópica e religiosa do cuidado, pois ainda existe uma vaga preferência por crianças em situações vulneráveis e por mães que trabalham (para crianças de 4 meses a 4 anos de idade) e tornou-se obrigatória na fase infantil, pois em 2013 houve alteração na LDB através da lei $\mathrm{n}^{\mathrm{o}}$ 12.796, de abril de 2013, segundo o Ministério da Educação, definindo a entrada de crianças na escola com 4 anos idade, fato importante que universaliza a garantia do direito à Educação Básica como direito fundamental das crianças.

Em 2017, foi publicado pelo Ministério da Educação do Brasil, a Base Curricular Nacional Nacional (BNCC), que contém os fundamentos da educação básica, da educação infantil aos anos finais do ensino médio. Para o BNCC, a educação infantil é contemplada por seis campos de experiência, baseados nos direitos da criança: conviver, brincar, participar, explorar, expressar e conhecer um ao outro (Brasil, 2017).

As discussões que permeiam a implementação do BNCC passaram por intensas discussões no Congresso Nacional, principalmente por fundamentalistas religiosos. Portanto, não foram contempladas no marco da Educação Básica, discussões sobre gêneros e sexualidades, um revés político-educacional que promove o declínio e a segmentação da educação, para que avanços importantes e discussões pertinentes sobre esse assunto se desfizessem.

Nas últimas décadas, a educação infantil no Brasil tem o desafio de ser garantida como um direito. Mas também se acrescenta o desafio de que esses direitos devem incorporar o respeito à diferença e à diversidade. Os estudos de Jane Felipe (2007, 2011), Claudia Vianna e Daniela finco (2009), apontam para o caráter heteronormativo e machista da educação infantil em diferentes aspectos. Especialmente, esses estudos apontam as influências dos discursos binários de gênero nos jogos e papéis de gênero que são considerados normativos para a infância. Os processos educacionais investigados revelam os preconceitos e as armadilhas do discurso da invisibilidade da sexualidade na infância e os papéis binários de gênero, marcados por argumentos biológicos ou moralista-religiosos, afirmados como verdadeiros.

Com o uso do termo "ideologia de gênero", grupos conservadores questionam e monitoram e controlam práticas educacionais na infância envolvidas com diferenças e diversidade sexual e de gênero como um direito de meninos e meninas. Esses grupos, envolvidos em movimentos religiosos radicais em defesa do familismo, criam terror e atribuem caráter criminoso às práticas educacionais abertas à diversidade, pois põem em risco a hegenomia heterossexual e patriarcal que garante a manutenção da família (Galindo et al., 2017; Junqueira, 2018).

Portanto, nosso principal objetivo é conhecer e identificar os processos de subjetivação de gênero e sexualidade das crianças presentes nas práticas discursivas de três educadoras de infantil. Procuramos possíveis respostas para as seguintes perguntas: Que problemas podem ser discutidos no decorrer desta investigação? Que transformações poderiam ser 
realizadas? Como as tecnologias de gênero atravessam os discursos dos educadores de infantil e suas práticas diárias.

\section{Método}

Utilizamos um caminho metodológico baseado na pesquisa-intervenção (Barros e Cesar, 2015) como principal metodologia cujo objetivo era analisar tecnologias nas produções discursivas, discursos sobre a infância na escola. Esses discursos foram produzidos em encontros e entrevistas com (três) professores de educação infantil cujas experiências relacionadas revelaram suas formas de subjetivação sobre sexualidades e gêneros na infância.

Segundo Barros e Cesar (2015), a pesquisa-intervenção tem como um de seus pressupostos um trabalho de atenção aberta no processo de acompanhamento de experiências. É uma perspectiva que entende que o conhecimento implica deslocar percepções, conceitos, valores, ideias e crenças em um processo de intervenção na maneira como os sujeitos se posicionam no mundo e em relação a si mesmos. Por isso, rompe com modelos de pesquisa baseados em neutralidade, afastamento e regularidade, colocando os pesquisadores como protagonistas principais.

Existe uma preocupação com os desvios, com os caminhos lançados na experiência de acompanhar os processos. Em nosso estudo de caso, procuramos acompanhar os processos de produção de conhecimentos e práticas sobre sexualidades e gêneros com crianças na perspectiva de educadores da infância.

O processo de educação das crianças investigado, atravessado pelos temas de gênero e sexualidade, teve como participantes três educadoras de educação infantil. Foram coletados dados em oficinas de debate, acompanhamento e compartilhamento dessas experiências. Realizamos três oficinas no total e acompanhamos as educadoras no contex to de suas práticas educacionais, estabelecendo diálogos constantes sobre o assunto.

Nossa inserção nesse campo de pesquisa se deve ao fato de um dos autores trabalhar como psicólogo num Centro de Educação Infantil, no qual as educadoras também são intervientes. As oficinas foram gravadas e transcritas e foram produzidos diários de campo sobre o acompanhamento das práticas. Além disso, foram realizadas entrevistas individuais com as três professoras, que foram gravadas e transcritas. Nesse contexto de pesquisa, o psicólogo / pesquisador está envolvido no gerenciamento de entrevistas e diálogos em oficinas que culminam em processos de afeto sobre as práticas educativas e os dispositivos de gênero e sexualidade.

Foi possível problematizar como a vida das educadoras infantis passa por sua prática profissional e pela vida das crianças, bem como as subjetivações de seus comportamentos sociais, como suas expressões de gênero e sexualidades na infância, são narradas e atravessadas por discursos. Marcadores sociais são enunciados nos espaços educacionais, nessa produção narrativa situando o discurso das educadoras como potentes intervenientes nesse contexto.

Nessa lógica, as entrevistas possibilitaram ao pesquisador ir além do que é dito propriamente, no qual o pesquisador é "imerso" nos afetos e interstícios que de um campo de experiências. Sugere-se uma investigação baseada em uma interlocução do conhecimento e dos efeitos que são (des) construídos ao longo das entrevistas. 
Para a análise do material, partimos do entendimento da multiplicidade de passagens que compõem um ambiente educacional. Estamos interessados em conduzir o método de pesquisa considerando a análise do discurso, a partir de Foucault (1996), no sentido de perceber através da linguagem quais são os métodos de produção discursiva nas agências relacionadas ao sexo, na interdição e nos campos que estão entrelaçados nas relações sociais.

\section{Das especificidades discursivas, o método crítico de análise do discurso baseia-se nas concepções nas quais a parte crítica da análise se une aos sistemas de cobertura do discurso; procura detectar, destacar esses princípios de ordenação, exclusão e rarefação do discurso. (Foucault, 1996, p. 69)}

Dessa forma, a análise baseou-se em um dos princípios propostos por Foucault (1996), sendo o da especificidade e o da exterioridade. Eles baseiam, respectivamente, no reconhecimento do discurso como força produtora de verdades e, na busca do conteúdo oculto do discurso, referindo-se às leis e à produção da verdade como margem das produções do desejo. Assim, destacaram-se eixos temáticos a partir da leitura do material registrado e coletado intencionalmente, para fazer emergir os princípios de especificidade, exterioridade e suas relações com a força de produção de verdades.

\section{Resultados e discussão}

Três educadoras de um Centro de Educação Infantil para crianças pequenas (de quatro meses a cinco anos) participaram da pesquisa. Entre os educadores convidados para a pesquisa, selecionamos intencionalmente educadoras com diferentes idades e horários de trabalho, uma recém-formada, 24 anos, outra que trabalhou por 25 anos na educação infantil, 48 anos e uma terceira, 51 anos e 17 anos trabalhando na educação infantil, também diretora do estabelecimento por 7 anos. Em primeiro lugar podemos destacar o discurso das educadoras infantis sobre jogos infantis e as expressões de gênero e sexualidade. Aqui também é destacado o problema do tempo normativo (cronológico) para ter experiências com seu corpo e desejo.

Em face do discurso sobre a "inocência” infantil, as educadoras interferem diretamente nas formas de brincar das crianças em contextos educacionais nos quais as diferenças mais significativas, percebidas, estão nas formas extremamente diferentes de brincar entre meninos e meninas, causando um ponto de desconforto para algumas educadoras e um ponto de "naturalidade" ou "neutralidade" em outros. Assim, uma educadora nos diz em relação ao brincar e as proibições de acordo com o sexo/gênero da criança:

Por exemplo, se um garoto pega uma boneca para brincar aqui e um pai o proíbe,
temos que ligar para o pai para conversar porque não tem nada a ver, a mesma coisa
com uma garota, ele tem o direito de brincar com o que quer. Gosto muito de me
mencionar como exemplo, nunca gostei de brincar com bonecas, dessas coisas, gostei
do baile e sou bem resolvida com a minha sexualidade [heterossexual], não há
influência em nada. (Educador da SIC 1 na transcrição da entrevista)

Podemos afirmar que essa posição é muito singular, pois as experiências pessoais dessa educadora fazem com que ela reflita o brincar das crianças do Centro de Educação Infantil e podemos perceber que, pelo contrário, tais educadoras marcam o lugar das mulheres e dos homens na sociedade como "naturais", provavelmente porque foram educadas assim. Com isso, "as demandas morais que tomam forma nas práticas institucionais de vigilância e controle, declaram a maneira literal como os jogos infantis são comumente interpretados por adultos que os educam” (Salgado e Lemos de Souza, 2018, p. 25 1), mantendo discursos 
que fragmentam os campos de experiência das crianças em relação ao brincar e a todas as demonstrações de afetos e comportamentos, estabelecidos por meio dos movimentos corporais das crianças, de acordo com os escritos de Vianna e finco (2009):

O corpo - seus movimentos, posturas, ritmos, expressões e linguagens - é, portanto, uma construção social que ocorre nas relações entre crianças e entre elas e adultos, de acordo com cada sociedade e cada cultura. Ele é produzido, moldado, modificado, treinado e decorado de acordo com parâmetros culturais. (Vianna e Finco, 2009, p. 271-272).

Em relação às expressões sociais associadas aos gêneros e às sexualidades representadas no modo de brincar das crianças, bem como às subjetivações propostas para o que é popularmente chamado de "jogo de menino" e "jogo de menina", podemos dialogar entre o conhecimento da importância do brincar na produção da infância, bem como $d \backslash a s$ questões destinadas à estagnação das subjetividades masculinas e femininas nos processos de educação infantil e os rumos desses apontamentos em que"entendemos, no entanto, que as crianças não apenas reproduzem as representações e práticas dos adultos, mas também interagem, negociam e, em muitos casos, violam regras impostas" (Silva e Luz, 2010, p. 24).

Podemos, então, pensar nas representações sociais expressas nos modelos de brincar, nas quais há necessidade de pensar nos processos de subjetivação associados às expressões contemporâneas de gênero, como tal, a geração de brincadeiras e a produção de infâncias no contexto social e/ou educacional.

O brinquedo funciona como uma forma de diferenciação entre masculino e feminino,
entre atividades divididas por gênero e orientação sexual, através da produção e
reprodução social de uma divisão de cómo se tornar homem e mulher, em um
determinado contexto histórico e cultural. Assim, cria-se um suposto universo
feminino, vinculado ao cuidado do lar, da família e da beleza; e outro homem,
associado a atividades que veem força física e esfera privada. (Cruz, Silva e Souza,
2012 , apud Castelar et al., 2015, p. 596)

Diante das propostas levantadas até o momento, é essencial discutir como "a inocência é consagrada como atributo emblemático da infância que, em sentido mítico, acaba se estabelecendo como uma espécie de 'natureza infantil"' (Salgado e Lemos de Souza, 2018, p. 243), o que nos faz pensar que a atribuição de inocência anula possibilidades de discussão de sexualidades e gêneros relevantes para a infância.

É no século XVII, na cultura ocidental, que prevalece a noção de inocência infantil, com a exaltação da fragilidade e vulnerabilidade das crianças. - filhos -, quando comparados aos anjos caídos, envoltos no manto sagrado da inocência como sinal de sua forma impecável. (Salgado e Lemos de Souza, 2018, p. 245)

Segundo os autores mencionados, "a infância, essa linha do tempo cronológica, representa o espaço vazio e inacabado de desenvolvimento, que deve caminhar progressivamente em direção ao nível mais avançado, representado pela vida adulta” (Salgado e Lemos de Souza, 2018, p. 248)

Podemos pensar na amplitude dos conteúdos de subjetivação e singularização que são desconsiderados pela disciplina dos corpos na esfera social e, como tal enunciação discursiva repressiva contribui nos processos de subjetivação, bem como nas sexualidades e em suas problematizações sociais, principalmente em produções binárias da Educação Infantil em relação à inscrição de crianças nos gêneros, nos processos de feminização e masculinização, segundo os escritos de Vianna e Finco (2009): 
O meticuloso processo de feminização e masculinização dos corpos, presente no controle dos sentimentos, no movimento corporal, no desenvolvimento de habilidades $e$ nos modelos cognitivos de meninos e meninas, está relacionado à força das expectativas que nossa sociedade e nossa cultura continua. Esse processo se reflete nos tipos de brinquedos permitidos e disponiveis: para que as crianças "aprendam", de maneira muito agradável e disfarçada, a se comportar como meninos e meninas "reais". (Vianna e Finco, 2009, pp. 272-273)

No emaranhado de discursos e afetos, propomos investigar e intervir a partir de experiências agenciadas com as educadoras da infâcia, mulheres que vivenciam e compartilham afetos, trazem suas experiências relacionadas a marcadores de gênero e sexualidades e que às vezes se reproduzem discursos hegemônicos sem a possibilidade de pensar sobre isso. Assim, narrar as experiências desses encontros, com base no acompanhamento das atividades de intervenção e em entrevistas com as educadoras, possibilitou produzir um olhar do pesquisador atravessado pelos afetos (ou descontentamentos) agregando experiências e trazendo novas perspectivas para educar, construindo possibilidades e organizando experiências intensas.

Assim, outro eixo que podemos destacar é o dos marcadores de identificação construídos pelos educadores para saber/prever como meninos e meninas se comportarão diante dos papéis hegemônicos de gênero e sexuais (regimes sexuais e de gênero). Podemos destacar os possíveis efeitos desses discursos no curso de vida de meninos e meninas.

Os educadores dizem que percebem se a criança pode "ser gay ou não" a partir de seus "modos" na Educação Infantil, todos os relatos trazem esse esse como fato comum entre os discursos. Quando questionada sobre o menino que brincava com a boneca, a educadora 2 diz:

\begin{abstract}
Bem, eu não acho que a família perceba nada disso, pelo menos ninguém nunca falou comigo, e eu também não iria falar comigo sobre o garoto que o filho brincava com uma boneca, você entende? Eu estava saindo. Eu e outros professores percebemos quando a criança era do jardim de infância, porque ela era diferente. (Educadora da SIC 2 na transcrição da entrevista)
\end{abstract}

A educadora 3 já mostra que existe esse tipo de discurso comparativo entre as crianças quando questionado sobre violência, em espaços educacionais, que pode ocorrer em relação às experiências das crianças baseadas nas expressões dos gêneros, conforme a seguinte história:

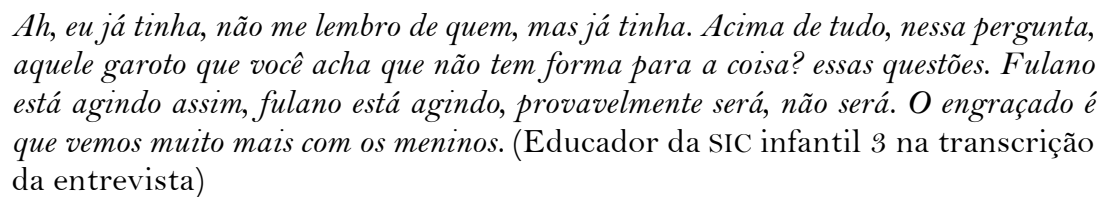

Nessas narrativas, observa-se claramente o quanto os "regimes sexuais" (Giddens, 2002) estão presentes na escola. Esse autor usa essa expressão para se referir à maneira como os corpos são disciplinados, enfatizando que a disciplina do corpo e sua relação com o agente social competente.

Podemos dizer que essas conversas das educadoras também têm o efeito de estigmatizar (Goffman, 1981), uma vez que colocam um rótulo, através de conversas que os desqualificam como inferiores e menosprezam a criança com características efeminadas, "brincando no pulso ou colorir como uma menina" (Educadora $\mathrm{n}^{\circ} 3$ ). 
Ao apresentar esses apontamentos, alguns critérios de produção de estigma são estabelecidos e claramente identificados socialmente no processo de escolarização, pela educadora ou pelas crianças, quando percebem as diferenças.

Nesse sentido, é importante problematizar o teor desses discursos e os efeitos que eles causam para quem os ouve, como determinantes nas ações que demandam intervenções sobre as diferenças no contex to escolar / educacional, como identificamos na deposição do educador de infância. 3:

Não! percebemos no desenho do menino, um desenho muito próximo ao da menina com mais detalhes. Ah, ele tinha um fato com Edson, ele reproduziu muito do lado efeminado, que desde o jardim de infância já percebemos que ele tinha essa tendência, ele tinha uma expressão diferente! (Educador infantil SIC 3)

Nesse sentido, mostramos que "isso compromete muito a vida de crianças e adolescentes com a sexualidade normalizada, pois, como afirmamos anteriormente, a escola é um dos espaços onde ocorrem diferentes formas de violência homofóbica” (Freitas e Brêtas, 2016, p. 107), nos jogos, naquilo que não pode ser dito pela criança e corrigido pelos olhos reguladores de seus educadores, é necessário priorizar que identifiquem a diferença como necessária para produzir sujeitos singulares e não pela via de estigmatização como ocorre atualmente.

A partir desses desdobramentos, podemos considerar como o machismo está estritamente associado aos processos de escolarização, mesmo de crianças pequenas, que reproduzem comportamentos no contexto educacional. Segundo os escritos de Felipe (2007), meninos entre 4 e 5 anos apresentam comportamentos homofóbicos, em que reafirmam uma identidade masculina hegemônica baseada no desprezo e na violência por tudo o que é diferente dela.

Ao considerar os processos de desenvolvimento humano e das infâncias, destaca-se a importância do brincar e a capacidade da criança de representar, a partir de atividades lúdicas, as expressões sociais que as educadores sugerem, nas quais é determinada uma série de comportamentos esperado da criança desde seu sexo biológico, incluindo como e com o que ela quer brincar e deve brincar.

Outro ponto de discussão mencionado pelas educadoras como algo a ser discutido sobre as representações de gênero na infância/lógica de gênero é a determinação das cores "para meninos" (azul) e "para meninas" (rosa). Quando questionada sobre a papel da escola diante das discussões sobre gênero e sexualidade uma educadora responde sobre as produções dos trabalhos pedagógicos para crianças:

Para mim não havia diferença, eu faria azul, rosa, vermelho, amarelo da cor que todo mundo quer, mas as crianças já vêm com isso de casa, a maioria já escolhe azul ou rosa, uma ou outra que é diferente. Seria importante trabalhar na escola, mas é como eu disse, para a sociedade em que vivemos, que é um trabalho muito difícil, porque já temos os problemas da educação, você entende? Que eles já têm suas dificuldades e se decidirmos colocar mais disso [questões de gênero] de frente, ficamos ainda mais complicados, porque temos uma direção e coordenação que pensam de maneira diferente, diferimos, porque, por exemplo, no ano passado eu estava enviar um caderno com um laço para os meninos, mas aí veio a coordenação: "ah, não! O pai não vai gostar, então você para e pensa: "ah, não combina com ele”, ele pensa, há aqueles pais do sexo masculino que iam criticar, ele ia "procurar problemas" ainda mais do que eu já tenho. Para mim é complicado aqui a questão da divisão de menino e menina, mesmo para a questão do banheiro, agora o que eu acredito, não sei se estou errado, mas essa divisão é tão necessária? Às vezes paro e penso: essa divisão sexual é 
necessária? Porque eu penso assim, eles ainda são filhos disso, eles têm essa noção? (Educadora de infantil da SIC 2)

O discurso dessa educadora está entrelaçado comos problemas em que a educação está imersa hoje em dia. Quando um professor se incomoda em relação às determinações dos papéis de gênero da infância, lhe é automaticamente proibido propor uma desconstrução, pois no final, é necessário propor reflexões e (des)construções no nível da instituição de ensino (estamos destacando a necessidade de um treinamento adequado que busca problematizar essas questões) para que haja a possibilidade de intervenção no nível social (micro-social) vinculado às possibilidades da escola em assumir esse papel de problematizar as discussões de gêneros, sexualidades e infâncias com os familiares das crianças, atingindo esferas macrossociais.

Nessa vertente discursiva, quando questionada sobre a possibilidade de propor uma educação que possibilite discutir as (des)construções sobre gênero, sexualidade e infância, uma educadora responde durante uma das entrevistas:

\begin{abstract}
Ah, eu não sei. Eduardo, porque passamos para outro ponto: damos a outra face? Se estivéssemos todos juntos, era uma coisa, mas uma única pessoa? e, a partir dessa investigação, podemos propor o seguinte: Será o papel da pedagogia e das áreas envolvidas com a educação propor reflexões sobre outras possibilidades de treinamento que discutam tais questões? (Educadora de infantil da SIC 2)
\end{abstract}

Quanto à nossa educadora, houve a possibilidade de debater com ela, questionando-a se ela acredita que essa seria uma boa perspectiva a ser abordada na educação infantil? Mesmo que nós façamos o enfrentamento da sociedade e com os pais? E a resposta foi a seguinte: "Seria importante e seria uma boa luta" (educadora infantil 2 SIC). Essa "luta", portanto, seria com a proposta de políticas educacionais e as opondo à hegemonia social que é entendida pela dicotomia sexo / gênero e pelas heterossexualidades dominantes.

\title{
4. Considerações finais
}

Os dados que emergiram da pesquisa-intervenção realizada neste estudo podem oferecer pistas sobre o processo educacional a respeito das diferenças sexuais e de gênero produzidas na educação infantil. Não foi possível, nem foi a intenção desta investigação, explicar todas as possibilidades de interpretação desses dados.

Reconhecemos os limites deste trabalho na generalização dos dados, mas o caminho escolhido foi o de abrir possibilidades para emergir tópicos para a realização de um debate educativo que inclua as diferenças de diversidade sexual e de gênero em seu cotidiano.

Durante o processo desta pesquisa, percebeu-se que é necessário prestar mais atenção às narrativas das professoras em sua tarefa de educar sobre gêneros e sexualidades. As educadoras infância que participaram desta pesquisa apresentaram, em seus discursos, a hegemonia que constantemente reproduz a desigualdade de gênero e os efeitos do machismo nas crianças e em si mesmos.

A linha tênue estabelecida entre educação/mulher/criança/direitos/sexualidades, buscou reconhecer as fragilidades do campo educacional. Isso nos permite, portanto, pensarmos em mulheres que têm suas experiências pessoais estabelecidas e articulam estratégias que consideram assertivas à educação ${ }^{3}$. Ao t”ornar pedagógico “o contexto educacional, os professores definem o espaço de aceitabilidade do que consideram normal e aceitável, tentam e tentam estabelecer normas sociais com os dissidentes. 
Foi durante o curso da pesquisa que pudemos observar o interesse das educadoras em discutir gêneros e sexualidades na infância, e suas experiências pessoais / profissionais, bem como os problemas que destacam, nos quais identificamos o potencial para criar estratégias de uma educação para a diversidade, com oportunidades de diálogo na infância e o processo escolar são abordados pelo binarismo de gênero.

Devemos insistir em um intenso debate da formação de professores sobre questões de idade e suas relações com os discursos da verdade (científicos, religiosos ou morais), nos quais são projetadas trajetórias de vida baseadas em gênero binário e heteronormatividade. Essa linha de trabalho sobre marcadores sociais e idade nem sempre é destacada pelos estudos feministas e queer. Idade, gênero e sexualidade desencadeiam discursividades naturalistas e têm uma linha tênue entre o moral e a crítica. Em outras palavras, o corpo não pertence aos meninos e meninas que os experimentam, mas faz parte do dispositivo da sexualidade que é construído na tentativa da sociedade de exercer poder sobre a vida. Nos discursos dos professores, os corpos de meninos e meninas estão sob a verdade do estado, da religião e da ciência.

As experiências e vozes das educadoras são destacadas, aproximando-as do debate atual sobre o momento político do país. Suas histórias apontam para esses desafios, além de trazer discursos envolvidos com a necessidade de estabelecer lugares fixos sobre sexualidade e gênero na infância. Acreditamos que esse é o paradoxo do sujeito na educação, que tem o desafio de superar os limites dos discursos da verdade, da construção da sexualidade e do gênero.

No decorrer das experiências e encontros com educadores de infantil, foram abertas oportunidades de diálogo sobre o que é transversal aos processos educacionais, momentos de grande importância que permeiam o dia a dia com a realidade educacional e a de processos de escolarização. As educadoras conseguiram falar abertamente sobre suas experiências pessoais devido à direção da dinâmica social na construção das identidades de gênero, em um espaço que vai além da carga de trabalho incessante e exaustiva, conseguiram falar sobre o que é percebido e não mencionado. Observamos que formas sutis e quase imperceptíveis de discriminação estão presentes nas escolas nas práticas de ensino, nas atividades didáticas e nos conteúdos curriculares que reforçam as diferenças sociais entre homens e mulheres, considerando-as naturais.

Consideramos também que há uma maior necessidade de conhecimento sobre o tema apontado pelas educadoras e presente na maneira como elas constróem seus discursos: como na busca constante de estabelecer, definir, ser verdade, como já foi observado em alguns discursos apresentados por elas, principalmente em relação aos corpos que, assim como os seus, discordam das normas aplicadas a gêneros e sexualidades.

No entanto, encontramos no sentido oposto desses discursos reflexões interessantes que identificam o potencial das educadoras em cooperar com uma educação gratuita e diversificada; portanto, identificamos possíveis análises interessantes das educadoras sobre os dispositivos escolares/familiares em relação ao gênero e sexualidade infantil. Para que, de fato, haja mudanças nas práticas educacionais, sugerimos entrar nos campos de formação de professores para a integração que faz parte da educação, assim, propomos uma formação que garanta e inclua o debate sobre gêneros e sexualidades e que rompa as barreiras das desigualdades sociais imposto pelo binarismo de gênero e pelas hegemonias das sexualidades. 
Por fim, reiteramos todas as problematizações já expostas neste artigo, com a tarefa de buscar uma proposta de políticas educacionais inclusivas que quebrem o binarismo de gênero, lutando contra toda e qualquer forma de opressão, violência, estigmatização ou exclusão social, principalmente contra pequenas infâncias. Reforçamos uma ampla ideia de educação inclusiva, na qual as diferenças não são naturalizadas em desigualdades, mas de uma perspectiva que afirma o potencial de existir e estar em uma comunidade de maneira respeitosa e saudável.

Afirmamos também que esta pesquisa, de importante teor discursivo para a educação, representa uma forma de resistência nos tempos sombrios de hoje e também resistimos às contribuições que serão fornecidas nas práticas educacionais dos professores/educadores que participaram, afinal, nesta pesquisa, que abrirá espaço para várias intervenções que serão organizadas e promoverá resistência também em nossos micro-relacionamentos.

Para que as mudanças ocorram, é necessário criar espaços de diálogo, produção e sentidos com as educadoras da infância: sobre como as desigualdades afetam e afetam suas relações cotidianas. Para isso é necessário romper com a naturalização da violência e das desigualdades sociais e sexuais.

\section{Referências}

Brasil. (2017). Base nacional comum curricular. Brasília: Ministério da Educação.

Buss-Simão, M. (2013). Relações sociais de gênero na perspectiva de crianças pequenas na creche. Cadernos de Pesquisa, 43(148), 176-197. https://doi.org/10.1590/So100-15742013000100009

Campos, M. M. (1999). A mulher, a criança e seus direitos. Cadernos de Pesquisa, 106, 117-127. https://doi.org/10.1590/So 100-15741999000100006

Castelar, M., Lemos, F. C. S., Khouri, J. G. R. e Andrade, T. (2015). Brinquedos e brincar na vida de mulheres educadoras negras. Revista Quadrimestral da Associação Brasileira de Psicologia Escolar e Educacional, 19(3), 595-602. https://doi.org/10.1590/2175-3539/2015/0193911

Didonet, V. (2001) Creche: A que veio, para onde vai. Revista Brasileira de Estudos Pedagógicos, $18,11-28$.

Felipe, J. (2007). Gênero, sexualidade e a produção de pesquisas no campo da educação: Possibilidades, limites e a formulação de políticas públicas. Revista Pro-posições 18(2), 7-87.

Felipe, J. (201 1). Erotização dos corpos infantis. En G. Lopes Louro, J. Felipe e S. Vilodre Goellner (Orgs.), Corpo, gênero e sexualidade: Um debate contemporânea na educação (pp. 53-65). Petrópolis: Vozes.

Foucault, M. (1996). A ordem do discurso. São Paulo: Loyola.

Foucault, M. (1999). A história da sexualidade I: A vontade saber. Rio de Janeiro: Graal.

Freitas, M J. D. e Brêtas, J. R. S. (2016). Estigma e preconceito na educação infantil e anos iniciais do ensino fundamental. Revista Gênero, 17(1), 105-122. https://doi.org/10.22409/rg.v17i1.862

Galindo, D., Cazeiro, F., Serra, A. G. e Lemos de Souza, L. (2017). LGBTs and gender banned? Genealogical notes about law projects in Brazil. Psicologia em Estudo, 22(2), 253-265. https://doi.org/10.4025/psicolestud.v22i2.33506

Giddens, A. (2002). Modernidade e identidade. Rio de Janeiro: Jorge Zahar. 
Gesser, M., Castro, L. O., Cord, D. e Nuernberg, A. H. (2012). Psicologia escolar e formação continuada de professores em gênero e sexualidade. Revista Semestral da Associação Brasileira de Psicologia Escolar e Educacional, 16(2) 229-236.

https://doi.org/10.1590/S1413-85572012000200005

Goffman, E. (1981). Estigma. Notas sobre a manipulação da identidade deteriorada. São Paulo: Lambert.

Junqueira, R. (2018). A invenção da "ideologia de gênero": A emergência de um cenário políticodiscursivo e a elaboração de uma retórica reacionária antigênero. Revista Psicologia Política, $18(43), 449-502$.

Lauretis, T. (1987). A tecnologia do gênero. Bloomington, IN: Indiana University Press.

Louro, G. L. (2000). O corpo educado: Pedagogias da sexualidade. Belo Horizonte: Autentica.

Maia, R. S. (2018). Corpos dissidentes: as identidades que "intertransitam" no cinema argentino contemporâneo. Revista Transversos, 14, 111-132. https://doi.org/10.12957/transversos.2018.38660

Paschoal, J. D. e Machado, M. C. G. (2009). A história da educação infantil no Brasil: Avanços, retrocessos e desafios dessa modalidade educacional. Revista HISTEDBR, 33, 78-95. https://doi.org/10.20396/rho.v9i33.8639555

Preciado, B. (2002). Manifiesto contra-sexual. Madrid: Opera Prima.

Rohden, F. (2009). Gênero, sexualidade e raça/etnia: Desafios transversais na formação do professor. Cadernos de Pesquisa, 39(136), 157-174. https://doi.org/10.1590/So10015742009000100008

Rodrigues, A., Zamboni, J., Lemos de Souza, L., Ferreir, M. e Salgado, R. (2018). Crianças desviadas, sexualidades monstruosas, educação pervertida: Paisagens alteritárias de infâncias. Periódicus, 9(1), 1-4. https://doi.org/10.9771/peri.v 1i9.26783

Rosa, R. V. M. (2011). Feminização do magistério: representações e espaço docente. Revista Pandora, 4, 1-19.

Rosemberg, F. (2002). Organizações multilaterais, estado e políticas de educação infantil. Cadernos de Pesquisa, 115, 25-63. https://doi.org/10.1590/So100-15742002000100002

Salgado, R. G. e Lemos de Souza, L. (2018). Gêneros, sexualidades e infâncias: Cenas de crianças na contramão da inocência. Childhood \& Philosophy, 14(29), 241-258.

https://doi.org/10.12957/childphilo.2018.30540

Silva, I. O. e Luz, I. R. (2010). Meninos na educação infantil: O olhar das educadoras sobre a diversidade de gênero. Cadernos Pagu, 34, 17-39.

https://doi.org/10.1590/So104-83332010000100003

\section{Breve CV dos autores}

\section{Eduardo Benedito Cólis}

Graduado en Psicología en la Universidade Paranaense. Psicólogo escolar / educativo vinculado al Centro Municipal de Educación Infantil Curumim (guardería y preescolar). Tiene una maestría en Psicología y Sociedad por la Universidade Estadual Paulista Julio de Mesquita Filho- Unesp, Assis. Vinculado al Grupo de Investigación de Psicología, Colectivos y Culturas Queer. Tiene experiencia en psicología escolar / educativa, desarrollo infantil y estúdios feministas. ORCID ID: https://orcid.org/OOOO-OOO3-17387216. Email: eduardocolis@outlook.com 


\section{Leonardo Lemos de Souza}

Doctor en Educación por la Universidade Estadual de Campinas. Pos doctorado en el Departamento de Psicología Básica de la Universitat de Barcelona. Profesor Asociado del Departamento de Psicología Social y del Programa de Posgrado en Pscología de la Universidade Estadual Paulista Julio de Mesquita Filho- Unesp. Vinculado al Grupo de Investigación de Psicología, Colectivos y Culturas Queer. ORCID ID: https://orcid.org/o000-0002-3331-1847. Email: leonardo.lemos@unesp.br 